\title{
Effects of temperature and food source on reproduction and longevity of aphid hyperparasitoids of the genera Dendrocerus and Asaphes
}

\author{
Jetske G. de Boer $(\mathbb{D} \cdot$ Lucia Salis • Ward Tollenaar • Lisa J. M. van Heumen • \\ Thibault P. M. Costaz $\cdot$ Jeffrey A. Harvey $\cdot$ Martine Kos $\cdot$ Louise E. M. Vet
}

Received: 16 November 2018/Accepted: 28 March 2019/Published online: 11 April 2019

(C) The Author(s) 2019

\begin{abstract}
Hyperparasitoids of aphid parasitoids commonly occur in (sweet pepper) greenhouses, and can pose a threat to effective biological control of aphids. Here, we studied life history characteristics of laboratory colonies of Dendrocerus spp. Ratzeburg (Hymenoptera: Megaspilidae) and Asaphes spp. Walker (Pteromalidae) that originated from a commercial sweet pepper greenhouse. We aimed to clarify how these two hyperparasitoid taxa can coexist inside greenhouses. Hyperparasitoids of both taxa have a
\end{abstract}

Handling Editor: Stefano Colazza

Electronic supplementary material The online version of this article (https://doi.org/10.1007/s10526-019-09934-4) contains supplementary material, which is available to authorized users.

J. G. de Boer $(\square) \cdot$ L. Salis · W. Tollenaar .

L. J. M. van Heumen . T. P. M. Costaz .

J. A. Harvey · M. Kos · L. E. M. Vet

Netherlands Institute of Ecology, Droevendaalsesteeg 10, 6708 PB Wageningen, The Netherlands

e-mail: j.deboer@nioo.knaw.nl

Present Address:

W. Tollenaar

Protix Biosystems, Industriestraat 3, 5107 NC Dongen,

The Netherlands

Present Address:

T. P. M. Costaz

Laboratory of Entomology, Wageningen University and

Research, Droevendaalsesteeg 1, 6708 PB Wageningen,

The Netherlands long lifespan that was extended significantly by food sources that are naturally available in a greenhouse environment, including aphid honeydew and sweet pepper flowers. Differences in sensitivity to decreased or increased temperatures did not appear to explain seasonal patterns in abundance of Dendrocerus spp. and Asaphes spp. in sweet pepper greenhouses. Instead, Dendrocerus spp. may have an advantage early in the season because it thrives on aphid honeydew, while Asaphes spp. may do better later in the season because of its long lifespan and extensive reproductive period.

Keywords Aphidius colemani $\cdot$ Myzus persicae . Fourth trophic level · Hymenoptera · Megaspilidae · Pteromalidae

Present Address:

M. Kos

Koppert Biological Systems, Veilingweg 14, 2651 BE Berkel en Rodenrijs, The Netherlands 


\section{Introduction}

Biological control of aphids with parasitoid wasps (Hymenoptera) is widely applied in greenhouse crops. Parasitoids in the family Braconidae (Aphidiidae) are among the most efficient biocontrol agents of aphids because of their short generation time and high reproduction rates so they can keep up with the very fast reproduction of their aphid hosts. However, these aphid parasitoids also have their own natural enemies, including fungi, predators and hyperparasitoids, which can greatly reduce the efficiency of biological control (Prado et al. 2015).

Hyperparasitoids are hymenopteran wasps that use other parasitoids as their host, i.e. they belong to the fourth trophic level. Obligate hyperparasitoids can only develop in or on another parasitoid, while facultative hyperparasitoids may develop as primary or secondary parasitoids (Sullivan and Völkl 1999). Aphid parasitoids are parasitized by a number of obligate hyperparasitoid species from four hymenopteran families. They either attack parasitoid (pre)pupae in mummified aphids (Pteromalidae and Megaspilidae), parasitoid larvae in live aphids (Figitidae), or can use both strategies (Encyrtidae) (Sullivan and Völkl 1999). Multiple hyperparasitoid species are often found in the same habitat, including greenhouses. Dendrocerus Ratzeburg (Megaspilidae) and Asaphes Walker (Pteromalidae) were found to be dominant in sweet pepper (Capsicum annuиm L.) greenhouses in British Columbia, but not in open field sweet pepper, suggesting that greenhouse conditions are favourable to these two taxa (Acheampong et al. 2012), or, vice versa, that greenhouse conditions are less favourable to other hyperparasitoid taxa.

Within the genus Dendrocerus, most European species are known to parasitize aphid mummies, and most species have a broad host range, i.e. they can parasitize combinations of many aphid species and primary parasitoids (Fergusson 1980). The same is true for the genus Asaphes, which has two European species that both parasitize a wide range of aphidparasitoid combinations. Both taxa are thus generalist hyperparasitoids of aphid mummies, in contrast to larval hyperparasitoids (Figitidae) that are often more specialized (Sullivan and Völkl 1999). Dendrocerus and Asaphes are hyperparasitoids that attack parasitoid (pre)pupae within mummified aphids, and both taxa have an ectoparasitic and idiobiont lifestyle
(Buitenhuis et al. 2017). Asaphes species are known to also host-feed on aphid mummies (Buitenhuis et al. 2017; Keller and Sullivan 1976), a phenomenon that appears to be absent in Dendrocerus species, except $D$. laticeps Hedicke (Mitsunaga et al. 2014). Host feeding is known to be associated with reproductive strategies in parasitoids (Heimpel and Collier 1996; Jervis and Kidd 1986), and this has also been shown for hyperparasitoids, for example in Gelis agilis Fabricius, a hyperparasitoid of Cotesia parasitoids (Harvey 2008; Harvey et al. 2012).

Coexistence of Dendrocerus and Asaphes species in greenhouses has been reported on several occasions (Acheampong et al. 2012; Bloemhard et al. 2014; Jacobson 2011; Nagasaka et al. 2010). In The Netherlands, D. aphidum appears to occur earlier in the season than A. suspensus in organic sweet pepper greenhouses (Bloemhard et al. 2014). This trend was also observed in Japan, where hyperparasitism by $D$. laticeps on banker plants in greenhouses occurred throughout the season, while A. suspensus Nees was only observed later in the season (Nagasaka et al. 2010). In open sweet pepper fields in British Columbia, Dendrocerus appears to arrive earlier in the season than Asaphes, with A. suspensus only recorded in August and September (Acheampong et al. 2012). However, the opposite pattern may also occur. In a British survey, A. suspensus was dominant in one sweet pepper greenhouse throughout the season, while at another site it was dominant until a mid-season insecticidal treatment, whereafter other species were observed (Jacobson 2011).

To better understand how Dendrocerus and Asaphes species can coexist, and to assess the factors that explain their seasonal trends, we set up a series of laboratory experiments. We first assessed the suitability of parasitized aphids and mummies of different ages as hosts for Dendrocerus spp. and Asaphes spp. We then evaluated their lifetime reproduction pattern, expecting Dendrocerus spp. to start reproduction earlier and Asaphes spp. to continue reproduction longer and have a higher lifetime fecundity, based on a recent comparison between D. carpenteri Curtis and A. suspensus (Buitenhuis et al. 2017). Because lifespan may be an important determinant of reproductive output in these taxa, as it is for some other (hyper)parasitoids (Jervis et al. 2008), we investigated the effect of food sources on longevity. Here, we focused on food sources that are naturally available to 
hyperparasitoids in a greenhouse environment, including sweet pepper flowers and aphid honeydew. We also determined the effect of temperature on hyperparasitoid oviposition and longevity, and we assessed cold tolerance of both taxa. Because seasonal trends suggest that Dendrocerus is more abundant earlier than Asaphes, we hypothesized that Dendrocerus spp. are more cold tolerant than Asaphes spp.

Our experiments were performed with laboratory colonies of Dendrocerus spp. and Asaphes spp. that originated from material collected in a sweet pepper greenhouse in The Netherlands. Although originally identified as D. aphidum and A. vulgaris (Fergusson 1980; Graham 1969), it became apparent that $D$. laticeps and $D$. carpenteri were also present in our Dendrocerus colony and A. suspensus was present in our Asaphes colony after completion of the experiments (tentative identifications by Frank van Veen at the University of Exeter, UK). Because these species were present in our colonies in unknown ratios, we will further refer to them as Dendrocerus spp. and Asaphes spp. This will not affect our conclusions because any differences between the two genera will be substantially larger than those within.

\section{Methods}

\section{Biological system}

For this study, we reared hyperparasitoids on pepper plants infested with tobacco aphids parasitized by Aphidius colemani Viereck because we wanted to approach the situation in sweet pepper greenhouses as closely as possible. Sweet pepper plants (Capsicum annuиm var. Maranello) were grown in a greenhouse and infested with Myzus persicae nicotianae, Sulzer when they were approximately eight weeks old. They were placed into large mesh cages (Bugdorm 4S4545, $47.5 \times 47.5 \times 47.5 \mathrm{~cm}$ ) holding aphid colonies, for 3-5 days. Then, two to three aphid-infested plants were transferred to a large mesh cage with A. colemani parasitoids for one day. Parasitized aphids developed into mummies over the course of the next seven days in another large mesh cage. This 'preparation' of pepper plants with A. colemani mummies was done six times per week to maintain a constant supply of fresh mummies for hyperparasitoid rearing. Hyperparasitoid colonies of Dendrocerus spp. and Asaphes spp. were started with adults emerged from hyperparasitized mummies collected in 2015 and 2016 in a commercial organic sweet pepper greenhouse in Oosterbierum, The Netherlands. Hyperparasitoids were kept in large fine mesh cages (Bugdorm 4F4545) and provided with water and honey, and pepper plants with $A$. colemani mummies were added daily. Plants were cut several times per week and transferred to emergence cages for development of adult hyperparasitoids. All insects were kept and experiments performed in climatised cabinets or chambers at $22 \pm 1{ }^{\circ} \mathrm{C}, 60-70 \% \mathrm{RH}$, and $16: 8 \mathrm{~h}$ L:D photoperiod.

\section{Experiments}

\section{Mummy age}

To study the suitability of different A. colemani host ages for parasitism by Dendrocerus spp. and Asaphes spp., late parasitized aphids (one day prior to mummification), early mummies (dead, but not yet fully mummified aphids, with a soft exoskeleton) and mummies of different ages were provided to hyperparasitoids. Aphidius colemani emerges from mummies five days post-mummification (13 days postoviposition), so we used mummified aphids that were parasitized 8-13 days before. One starting batch of mummies was obtained by infesting three five-weekold sweet pepper plants with 170 adult aphids each at day zero. The next day, adult aphids were removed and approximately 300 newly produced nymphs per plant remained. Two days later, $80 \mathrm{~A}$. colemani parasitoids were added to each plant for $8 \mathrm{~h}$. Seven days after parasitism, late parasitized aphids were collected and tested in the experiment. Early mummies and part of the fully formed mummies that developed over the next $24 \mathrm{~h}$ were tested eight days post-parasitism. Remaining mummies were collected from the plants and stored in a Petri dish kept at $22 \pm 1{ }^{\circ} \mathrm{C}$ for use on the following five days.

Each test day, five mated Dendrocerus spp. and Asaphes spp. females of 2-4 days old were placed individually in a special Petri dish with a circular mesh membrane in the lid $(10 \mathrm{~cm}$ diameter, $4 \mathrm{~cm}$ high; Insect Breeding dish, SPL Lifesciences Co. Ltd, Korea, further referred to as insect breeding dish) and provided with a small droplet of honey on the mesh. Five hosts were provided per female. Late 
parasitized aphids were provided on sweet pepper leaves, which were stuck to the lid for Asaphes spp. because we thought this could enhance parasitism rate. Mummies were placed on a filter paper (Whatman, grade 1) on the bottom of the dish for Dendrocerus spp., and on a memo paper stuck to the lid for Asaphes spp. After 6 h, hyperparasitoid females were removed. Because early mummies develop into mummies rapidly, exposure time was only $2.5 \mathrm{~h}$. For four weeks, we checked emergence of A. colemani or hyperparasitoids daily to determine hyperparasitism rate (the proportion of hyperparasitoids of the total number of 'alive' mummies). Mummies that did not emerge were counted as dead mummies because we did not determine whether they contained A. colemani or hyperparasitoid offspring (see "Results" section).

\section{Reproductive pattern and lifetime fecundity}

Individual newly emerged hyperparasitoid females were placed in insect breeding dishes, together with three males, and a small droplet of honey provided on the lid. Males were removed after one day. The females were presented with 20 A. colemani mummies each day, including the first day, until the female died. In this experiment (and the following ones), mummies were collected eight days post-parasitism because this host age was suitable for both hyperparasitoid taxa (see "Results" section). Mummies were offered on the bottom of the insect breeding dish on a filter paper because offering upside down in the first experiment did not improve parasitism substantially (see "Results" section). Each daily set of 20 mummies was transferred to a Petri dish $(9 \mathrm{~cm}$ diameter, VWR Scientific) for development of offspring. Emergence and sex ratio of hyperparasitoids was recorded after approximately four weeks. A subset of offspring was weighed on a microbalance (Mettler Toledo MT5, $1 \mu \mathrm{g}$ accuracy) after drying them in a ventilated oven at $70{ }^{\circ} \mathrm{C}$ for three days (152 Dendrocerus spp. and 187 Asaphes spp. individuals). Developmental time of a subset of offspring was also recorded by monitoring emergence daily (110 Dendrocerus spp. and 40 Asaphes spp. individuals). Seven Dendrocerus spp. and ten Asaphes spp. females were used in this experiment, but two Asaphes spp. females were excluded from the analyses because one unexpectedly died after reproducing for two days and one did not produce any offspring for 36 days after reproducing on days two and three.

\section{Oviposition at lower temperature}

To evaluate whether oviposition occurs at lower temperatures, we compared parasitism rates of Dendrocerus spp. and Asaphes spp. females at $5^{\circ} \mathrm{C}$, $10{ }^{\circ} \mathrm{C}$, and $15^{\circ} \mathrm{C}$ to the control situation at $22{ }^{\circ} \mathrm{C}$. Individual females of 2-4 days old were placed in insect breeding dishes with five newly formed mummies on a filter paper, and provided with honey. Dishes were placed inside climatised cabinets at the three treatment temperatures under conditions that were otherwise the same as those at $22{ }^{\circ} \mathrm{C}$. After $24 \mathrm{~h}$, females were removed and dishes with mummies were kept at $22{ }^{\circ} \mathrm{C}$ to determine parasitism rate after four weeks. Sixteen to 20 replicates were done for Dendrocerus spp. at each temperature, and nine to 17 replicates for Asaphes spp.

\section{Effect of food sources on longevity}

Newly emerged hyperparasitoid females were placed individually in insect breeding dishes. The wasps had access to one of the following food sources: (1) water provided on a small ball of cotton; (2) honeydew from $M$. persicae on a piece of sweet pepper leaf with aphids removed (approximately $16 \mathrm{~cm}^{2}$, and excluding the main vain of the leaf); (3) an open flower of sweet pepper, containing floral nectar and pollen; (4) five mummies of A. colemani on M. persicae; (5) a combination of the honeydew, flower and mummy treatments. These five treatments were compared to (6) a positive control consisting of a small droplet of honey, and (7) a negative control without food or water. Treatments (2) to (6) did not receive additional water. Mortality of the insects was checked daily and food sources were replaced three times per week. We performed 16-25 replicates per food source per hyperparasitoid taxa. Dead hyperparasitoids were collected individually in microcentrifuge vials and weighed on a microbalance as above because larger hyperparasitoids may live longer. Weight data were available for a subset of replicates (77 Asaphes spp. females and 97 Dendrocerus spp. females). 


\section{Effect of temperature on longevity}

Methods for longevity measurements at different temperatures followed those for the effect of food sources on longevity. At $10{ }^{\circ} \mathrm{C}$, all insects were provided with a filter paper moistened with water, and honey was applied to half of the dishes. Sixteen replicates were done per hyperparasitoid taxa for each treatment at $10{ }^{\circ} \mathrm{C}$. Light settings at $10^{\circ} \mathrm{C}$ were 12:12 h L:D to mimic greenhouse conditions after harvesting the final crop, which is commonly done in November in The Netherlands. In a separate experiment, longevity at $30{ }^{\circ} \mathrm{C}$ was compared to $22{ }^{\circ} \mathrm{C}$, in the presence of honey. Sixteen to 18 replicates were done at both temperatures for both taxa. Survival was monitored daily in all experiments.

\section{Cold tolerance}

Chill coma and chill coma recovery experiments were performed according to methods by Hazell et al. (2008) with two to four-day old females. For the chill coma, the hyperparasitoids were first kept inside the system at $20{ }^{\circ} \mathrm{C}$ for $10 \mathrm{~min}$, then the temperature was lowered to $10{ }^{\circ} \mathrm{C}$ in $10 \mathrm{~min}$, and to $-2{ }^{\circ} \mathrm{C}$ over the next $75 \mathrm{~min}$. Hyperparasitoid activity was monitored by a video set-up, and the temperature where they last walked was recorded. For the chill coma recovery, the temperature was raised from -2 to $10{ }^{\circ} \mathrm{C}$ over a period of $35 \mathrm{~min}$, and then to $20^{\circ} \mathrm{C}$ in $1 \mathrm{~min}$, recording the temperature at which the hyperparasitoids started walking again. For each trial, four hyperparasitoids of the same taxa were used at the same time, and eight replicate sets were done for Dendrocerus spp., and five for Asaphes spp. In the analysis of the data, 31 Dendrocerus spp. females (one individual died) and 20 Asaphes spp. females were used. For the chill coma, four Dendrocerus spp. females that stopped moving at a temperature above $18{ }^{\circ} \mathrm{C}$ were excluded from the analysis, because the cessation of movement may potentially be caused by external factors such as physical damage.

Statistical analysis

\section{Mummy age}

Replicates on parasitized aphids and on the oldest mummies were excluded from statistical analyses because these host stages were unsuitable for hyperparasitism. Replicates on early mummies were also excluded because they were exposed for 2.5 instead of $6 \mathrm{~h}$, compromising statistical comparison. Within the mummy age range of 8-12 days post-parasitism (M0M4), we tested the effects of hyperparasitoid taxa and mummy age (as a continuous variable) and their interaction on the proportion of hyperparasitized mummies and proportion of dead mummies with generalized linear models (GLM) with a binomial error structure and using a logit link function. The first model showed minor overdispersion and the second model minor underdispersion, probably due to the low number of replicates per hyperparasitoid taxa per host age $(\mathrm{N}=5$; models with an estimated dispersion parameter yielded qualitatively similar results).

\section{Reproductive pattern}

In the lifetime fecundity experiment, we determined longevity, realised fecundity (i.e. total offspring), median and maximum daily fecundity, first day of oviposition, oviposition period, and post-oviposition period. These data were not normally distributed and the effect of hyperparasitoid taxa was tested with a permutation test to compare medians for each parameter ( $\mathrm{R}$ package rcompanion, function percentileTest, $r=10000$ ) (Mangiafico 2018). This test was also used to compare median developmental time of offspring between taxa. Effects of taxa and sex and their interaction on dry body mass were tested with a twoway ANOVA followed by post-hoc pairwise comparisons (Tukey's honestly significant difference test, further referred to as Tukey's HSD). Finally, we tested per taxa whether longevity and fecundity were correlated with a Spearman rank correlation test.

\section{Oviposition at low temperatures}

We excluded the Asaphes spp. data from statistical analysis because a substantial number of Asaphes spp. females did not reproduce for unknown reasons. The effect of oviposition temperature on the proportion hyperparasitism by Dendrocerus spp. was tested with a generalized linear model (binomial error structure, logit link function), including only replicates that produced at least one offspring. 


\section{Longevity}

We used Cox proportional hazard models to analyse the effect of taxa and food source on longevity ( $R$ package survival) (Therneau 2015). Right-censored data were included when a hyperparasitoid escaped or was accidentally killed (11 out of 258 replicates). We first compared the interaction model (taxa (as strata) $\times$ food) with the additive model (taxa (as strata) + food). The effect of food sources on longevity was then analysed in separate models for Dendrocerus spp. and Asaphes spp., followed by pairwise comparisons among food sources based on log-rank tests (using R package survminer) (Kassambara and Kosinski 2018), adjusting for multiple comparisons with false discovery rate (Benjamini and Hochberg 1995). The effect of weight as a covariate was tested in separate models because it was available for a subset of replicates only. Longevity at $10{ }^{\circ} \mathrm{C}$ was also analysed with Cox proportional hazard models (taxa (as strata) $\times$ food), including censored data (six out of 66 replicates), and followed by pairwise comparisons with exact twosample log-rank tests (R package coin) (Hothorn et al. 2006). The effect of temperature (as a factor with three levels: 10,22 and $30{ }^{\circ} \mathrm{C}$ ) on longevity was also tested with Cox proportional hazard models (taxa (as strata) $\times$ temperature), including censored data (four out of 100 replicates).

\section{Cold tolerance}

Wilcoxon rank sum tests were used to evaluate whether Asaphes spp. and Dendrocerus spp. had different cold tolerance and recovery temperatures. All statistical analyses were performed with $\mathrm{R}$ version 3.5.0 (R Core Team 2018).

\section{Results}

Reproduction

Suitability of different host ages

Neither Dendrocerus spp. nor Asaphes spp. were able to reproduce in parasitized aphids (supplementary material Fig. S1). Dendrocerus spp. was able to reproduce in early mummies but no Asaphes spp. offspring emerged from this host stage. Fully formed mummies at 8-12 days post-parasitism (M0-M4) were suitable for both hyperparasitoid taxa. In these mummies, Asaphes spp. had substantially lower parasitism rates (median 0.25) than Dendrocerus spp. (median 1.00). Hyperparasitism rate of Dendrocerus spp. dropped in mummies 12 days post-parasitism (M4), while Asaphes spp. had a more or less constant hyperparasitism rate over mummy ages $\left(\mathrm{GLM}\right.$, taxa $\times$ age: $\left.\chi_{1}^{2}=36.696, \mathrm{P}<0.001\right)$. The oldest mummies (13 days post-parasitism, M5), were unsuitable for Dendrocerus spp., while one of the five Asaphes spp. females produced a single offspring. The proportion dead hosts was stable over mummy ages M0-M4 and was slightly higher in Asaphes spp. (median 0.20) than in Dendrocerus spp. (median 0) (supplementary material Fig. S1, GLM, age: $\chi_{1}^{2}=0.072, \mathrm{P}=0.788$; taxa: $\chi_{1}^{2}=3.603, \mathrm{P}=0.058$ ).

\section{Reproductive pattern and lifetime fecundity}

Reproduction started earlier in Dendrocerus spp. than in Asaphes spp., with six out of seven Dendrocerus females reproducing on the first day against one of eight Asaphes females. Dendrocerus spp. produced half of their offspring within 4-5 days, while the reproductive period of Asaphes spp. was much longer. In total, Asaphes spp. produced more than twice as many offspring than Dendrocerus spp. (Table 1). Realised fecundity was significantly positively correlated with longevity in Asaphes spp. (supplementary material Fig. S2, Spearman rank correlation, rho = $0.95, \mathrm{P}=0.001$ ), but not in Dendrocerus spp. (rho = $-0.65, \mathrm{P}=0.115)$. The proportion male offspring was nearly twice as small in Dendrocerus spp. than in Asaphes spp. (Table 1, P=0.053). Despite these clearly different lifetime reproductive patterns (supplementary material Fig. S3), medians of none of the measured parameters were significantly different between hyperparasitoid taxa (Table 1, percentile test, all $\mathrm{P}>0.05$ ). In contrast, in the longevity experiment without hosts (see below), Asaphes spp. lived significantly longer than Dendrocerus spp. (Table 1, percentile test, $\mathrm{P}=0.001$; see also Fig. 2). With hosts, hyperparasitoids of both taxa lived approximately half as long than without hosts, suggesting a cost of reproduction in terms of longevity. Adult dry body weight of offspring was significantly different 
Table 1 Overview of parameters measured for Dendrocerus spp. and Asaphes spp. in the lifetime fecundity experiment, provided daily with $20 \mathrm{M}$. persicae/A. colemani mummies until death

\begin{tabular}{|c|c|c|c|}
\hline Life history parameter & Dendrocerus spp. $(\mathrm{N}=7)$ & Asaphes spp. $(\mathrm{N}=8)$ & P-value ${ }^{a}$ \\
\hline Longevity (days) & $15(12-20)^{\mathrm{b}}$ & $26.5(5-95)$ & 0.060 \\
\hline Longevity (days) in absence of hosts ${ }^{c}$ & $30(16-60)$ & $56(9-82)$ & 0.001 \\
\hline Realised fecundity & $67(14-107)$ & $143.5(21-786)$ & 0.078 \\
\hline Median daily fecundity & $3.5(0-10)$ & $7(2-11)$ & 0.171 \\
\hline Maximum daily fecundity & $10(6-18)$ & $14(9-20)$ & 0.224 \\
\hline First day of oviposition & $1(1-2)$ & $2(1-3)$ & 0.613 \\
\hline Post-oviposition period (days) & $2(0-5)$ & $3(0-16)$ & 0.738 \\
\hline Oviposition period (days) & $12(9-19)$ & $19.5(3-77)$ & 0.098 \\
\hline Sex ratio (prop. males) ${ }^{\mathrm{d}}$ & $0.37(0.25-0.84)$ & $0.71(0.54-0.90)$ & 0.053 \\
\hline \multicolumn{4}{|l|}{ Offspring measurements } \\
\hline Dry weight male offspring $(\mu \mathrm{g})^{\mathrm{e}}$ & $\begin{array}{l}27.62 \pm 1.32 \\
(\mathrm{~N}=71)\end{array}$ & $\begin{array}{l}30.37 \pm 0.76 \\
(\mathrm{~N}=141)\end{array}$ & $\begin{array}{l}\text { 2-way ANOVA: } \\
\text { Taxa: } \mathrm{F}_{1,335}=4.113, \mathrm{P}=0.043\end{array}$ \\
\hline Dry weight female offspring $(\mu \mathrm{g})^{\mathrm{e}}$ & $\begin{array}{l}33.44 \pm 1.16 \\
(\mathrm{~N}=81)\end{array}$ & $\begin{array}{l}40.96 \pm 1.68 \\
(\mathrm{~N}=46)\end{array}$ & $\begin{array}{l}\text { Sex: } F_{1,335}=46.156, P<0.001 \\
\text { Taxa } \times \text { sex: } F_{1,335}=3.98, P=0.047\end{array}$ \\
\hline Developmental time (days) ${ }^{\mathrm{f}}$ & $12(10-15)$ & $19(18-20)$ & $<0.001$ \\
\hline
\end{tabular}

${ }^{\mathrm{a}} \mathrm{P}$-values for comparing medians of Dendrocerus spp. and Asaphes spp. (percentile test)

${ }^{\mathrm{b}}$ Median and range (min-max), except for dry weight: mean $\pm \mathrm{SE}$

${ }^{\mathrm{c}}$ Longevity with honey but without hosts (no reproduction); data derived from longevity experiment on food sources (Fig. $2, \mathrm{~N}=21$ for both taxa)

${ }^{\mathrm{d}}$ Replicates that did not produce any daughters were excluded (one Dendrocerus and two Asaphes females)

${ }^{\mathrm{e}} \mathrm{A}$ subset of male and female offspring was weighed

${ }^{\mathrm{f}}$ Developmental time was determined for a subset of 110 Dendrocerus and 40 Asaphes offspring (mixture of males and females)

between taxa and sexes (Table 1, supplementary material Fig. S4, two-way ANOVA, taxa: $\mathrm{F}_{1,335}=4.113, \quad \mathrm{P}=0.043 ; \quad$ sex: $\quad \mathrm{F}_{1,335}=46.156$, $\mathrm{P}<0.001 ;$ taxa $\times$ sex: $\mathrm{F}_{1,335}=3.98, \mathrm{P}=0.047$ ). Asaphes spp. were heavier than Dendrocerus spp. This was particularly clear for Asaphes spp. females that were much heavier than males (Tukey's HSD, $\mathrm{P}<0.001$ ), while the difference between the sexes was less obvious but also significant in Dendrocerus spp. (Tukey's HSD, $\mathrm{P}=0.003$ ). Dendrocerus spp. offspring developed significantly faster than Asaphes spp. offspring (Table 1 , percentile test, $\mathrm{P}<0.001$ ).

\section{Oviposition at low temperature}

Both taxa were able to reproduce when kept at $5{ }^{\circ} \mathrm{C}$ for $24 \mathrm{~h}$ : one of 16 Asaphes spp. females and four of 20 Dendrocerus spp. females produced offspring. Overall, parasitism success of Asaphes spp. was low in this experiment with only 13 out of 56 females reproducing over the four temperatures at a median hyperparasitism rate of 0.30 (Fig. 2). Dendrocerus spp. hyperparasitism success was higher overall (median 1.0) and positively affected by temperature at oviposition (GLM, $\left.\chi_{1}^{2}=15.846, \mathrm{P}<0.001\right)$. The proportion Dendrocerus spp. females that produced any offspring also increased rapidly with temperature (Fig. 2).

\section{Longevity}

\section{Longevity on different food sources}

Asaphes spp. and Dendrocerus spp. longevity was differentially influenced by the seven food sources that we tested (Fig. 2, taxa (as strata) $\times$ food: $\chi_{6}^{2}=44.34$, $\mathrm{P}<0.001$ ). The effect of food sources on longevity was further analysed separately for the two taxa.

Food source had a highly significant effect on longevity of Dendrocerus spp. females (Fig. 2a, 


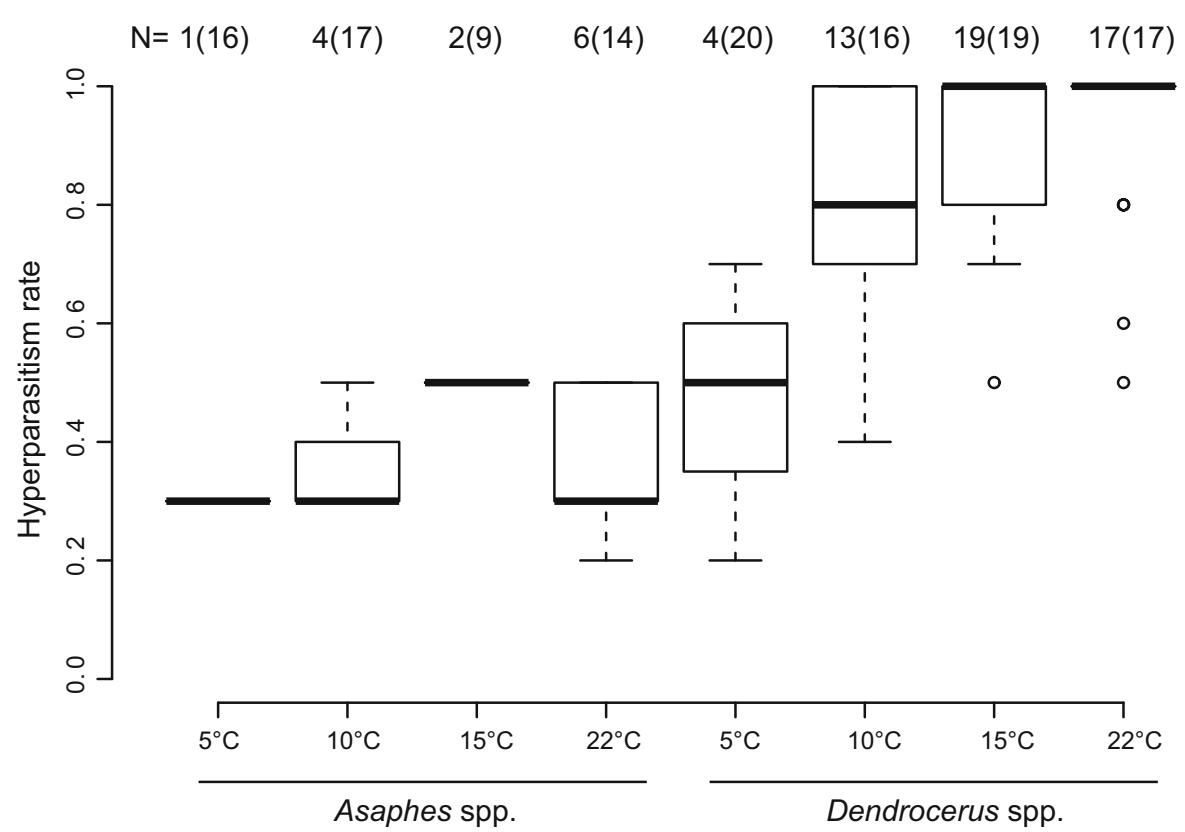

Fig. 1 Effect of temperature at oviposition $\left(5,10,15\right.$ or $\left.22{ }^{\circ} \mathrm{C}\right)$ on parasitism success of Asaphes spp. and Dendrocerus spp. hyperparasitoids on A. colemani mummies developed on $M$. persicae. Numbers above boxplots indicate how many females produced at least one offspring, with the total number of females exposed to hosts in brackets. Females that did not reproduce (i.e. hyperparasitism rate $=0$ ) were excluded. In Dendrocerus spp., temperature had a significant effect on hyperparasitism rate

$\left.\chi_{6}^{2}=194.3, \mathrm{P}<0.001\right)$. Longevity was shortest when Dendrocerus spp. were given no food or water (control), water or A. colemani mummies. Among these three treatments, lifespan on water was significantly longer than that on the control $(\mathrm{P}=0.015)$, while lifespan on mummies was intermediate to both ( $\mathrm{P} \geq 0.098$ ). Dendrocerus spp. females lived significantly longer on sweet pepper flowers or the combination of mummies, flowers and honeydew on sweet pepper leaves (all $\mathrm{P}<0.001$ ). Longevity was significantly higher still when Dendrocerus spp. was provided with $M$. persicae honeydew on sweet pepper leaves or honey (all $\mathrm{P}<0.01$ ).

Food source also had a significant effect on longevity of Asaphes spp. females (Fig. 2b, $\left.\chi_{6}^{2}=136.86, \quad \mathrm{P}<0.001\right)$. Longevity was shortest when Asaphes was given no food or water (control) or water only. Asaphes longevity increased slightly but significantly on A. colemani mummies $(\mathrm{P} \leq 0.049)$. Asaphes females lived significantly longer on honeydew of $M$. persicae on sweet pepper leaves, while
(GLM, $\left.\chi_{1}^{2}=15.846, \mathrm{P}<0.001\right)$. Results for Asaphes spp. were not statistically analysed because of the low number of females that reproduced. In boxplots in Figs. 1, 2, 3, the thick horizontal line marks the median, upper and lower limits of boxes represent the 25th and 75th percentiles of data, whiskers extend to the furthest datapoint from the upper or lower limits to a maximum of 1.5 times the size of the box, and 'outliers' are shown as open circles (default settings for boxplot in $\mathrm{R}$ )

longevity on sweet pepper flowers was significantly higher still (pairwise comparison with honeydew, $\mathrm{P}=0.048$ ). Longevity on honey was statistically similar to and intermediate between honeydew and flowers ( $\mathrm{P} \geq 0.088$ ). The combination of mummies, flowers and $M$. persicae honeydew resulted in the significantly highest longevity compared to any other food source $(\mathrm{P} \leq 0.028)$.

Weight data were available for a subset of replicates (97 of 139 Dendrocerus spp. and 77 of 119 Asaphes spp. females). Analysis of these subsets showed that weight had a marginally significant positive effect on longevity of Dendrocerus spp. females $\left(\chi_{1}^{2}=3.96, \mathrm{P}=0.047\right)$, while the interaction between weight and food sources was not significant $\left(\chi_{6}^{2}=2.52, \mathrm{P}=0.866\right)$. Weight did not have a significant effect on longevity of Asaphes spp. $\left(\chi_{1}^{2}=0.67\right.$, $\mathrm{P}=0.413)$. 
(a) Dendrocerus spp.

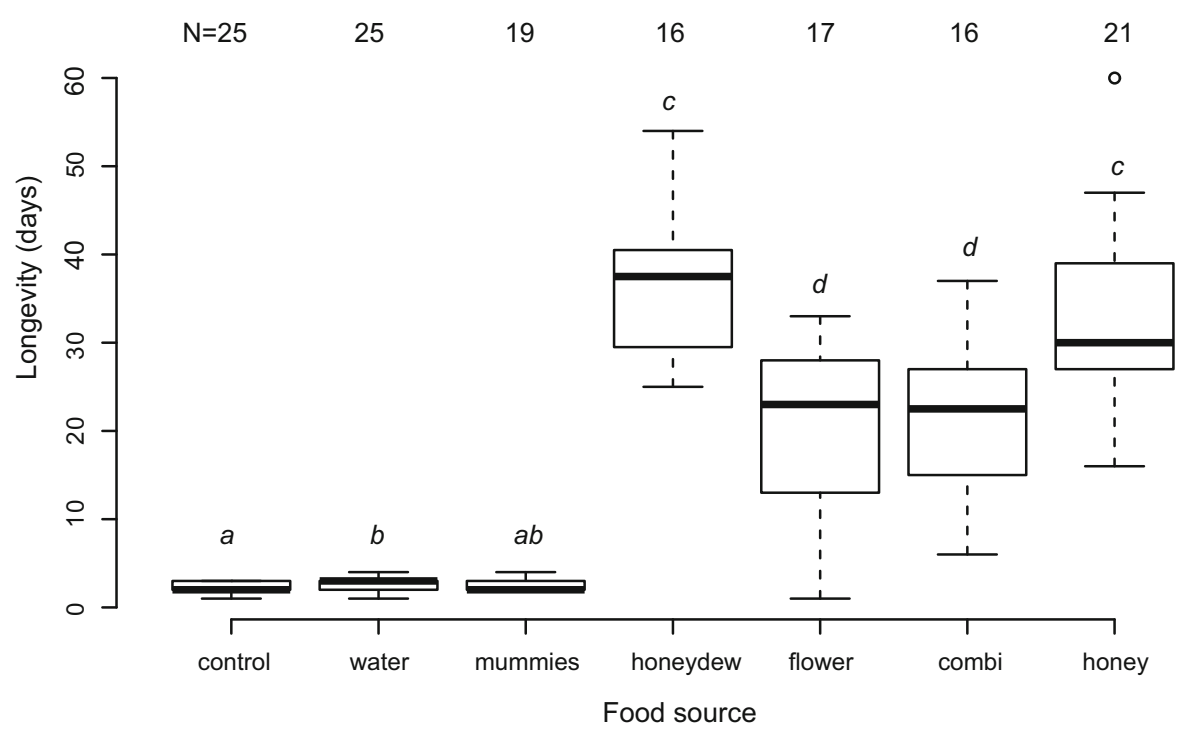

(b) Asaphes spp.

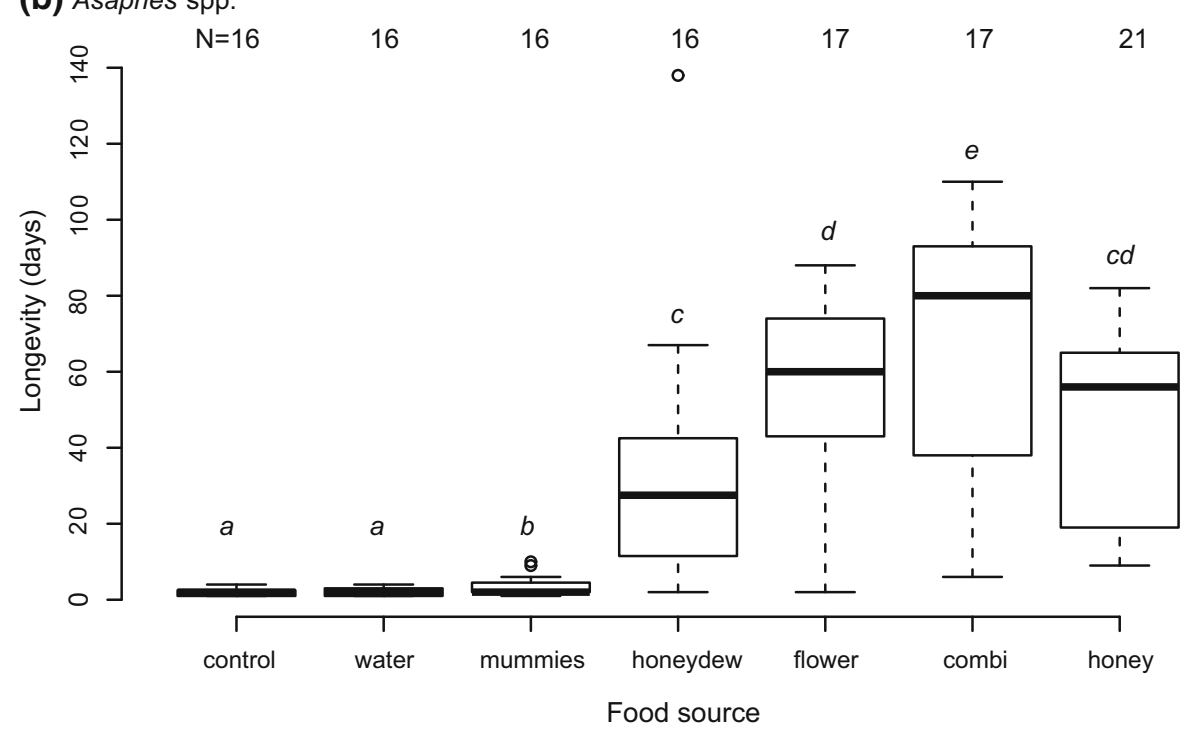

Fig. 2 Longevity of hyperparasitoid females of Dendrocerus spp. a and Asaphes spp. b on seven different food sources. Food sources included: control (no food or water), water, mummies (five A. colemani mummies developed on $M$. persicae), honeydew (of $M$. persicae aphids on sweet pepper leaves), flower (one sweet pepper flower containing nectar and pollen), combi (combination of mummies, honeydew and flower), honey (a small drop of honey). Numbers above boxes represent the

\section{Longevity at lower and higher temperatures}

At $10{ }^{\circ} \mathrm{C}$, honey significantly increased longevity of both hyperparasitoid taxa (supplementary material Fig. S5, food: $\chi_{1}^{2}=62.141, \mathrm{P}<0.001$; taxa (as strata) number of replicates. Within species, food source had a significant impact on longevity (Dendrocerus spp. $\chi_{6}^{2}=194.3$, $\mathrm{P}<0.001$; Asaphes spp. $\left.\chi_{6}^{2}=136.86, \mathrm{P}<0.001\right)$. Different lower-case letters above boxes indicate significant pairwise differences within species $(\mathrm{P}<0.05)$, see supplementary Table S1 for exact pairwise P-values. For an explanation of boxplots, see Fig. 1

$\times$ food: $\chi_{1}^{2}=1.623, \mathrm{P}=0.203$ ). On water only, Asaphes spp. females lived approximately six days and Dendrocerus spp. females 6.5 (exact two-sample log-rank test, $\mathrm{Z}=-1.386, \mathrm{P}=0.172$ ). On honey, Asaphes spp. females lived significantly longer 


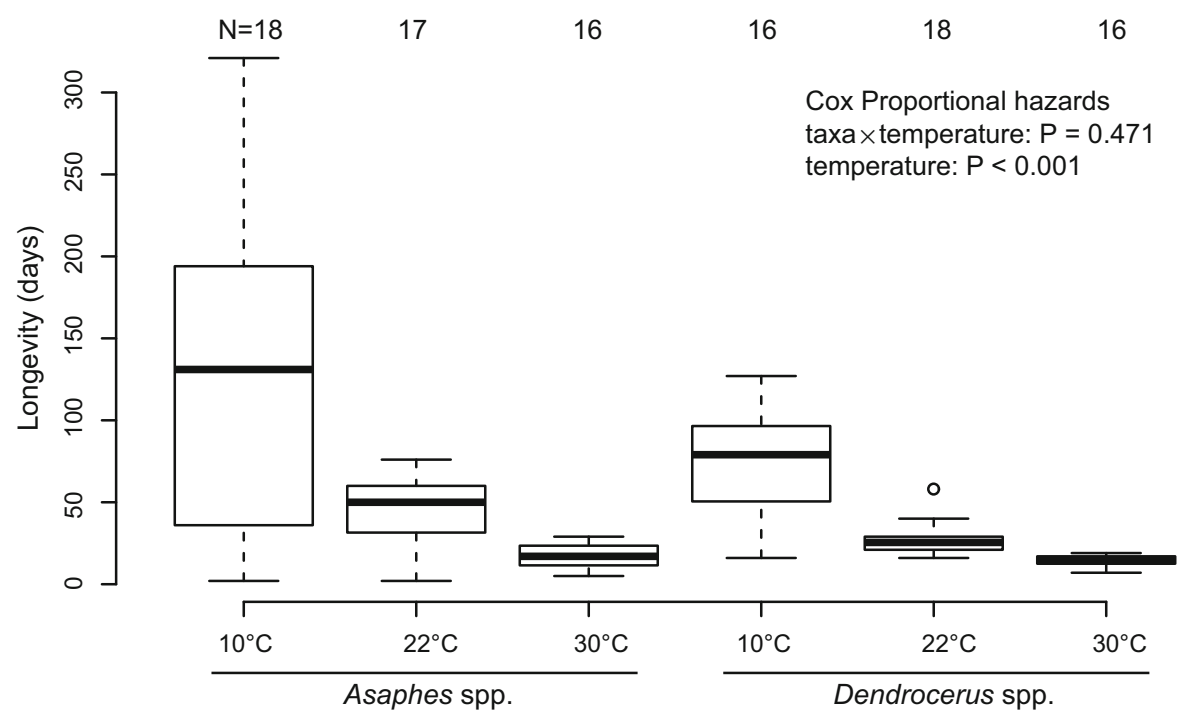

Fig. 3 Longevity of Asaphes spp. and Dendrocerus spp. females at $10{ }^{\circ} \mathrm{C}, 22{ }^{\circ} \mathrm{C}$ and $30^{\circ} \mathrm{C}$ in the presence of honey. Numbers above boxplots indicate the number of replicates. Temperature had a significant effect on life expectancy

(median 131 days) than Dendrocerus spp. females (median 79 days) (exact two-sample log-rank test, $\mathrm{Z}=2.337, \mathrm{P}=0.015$ ).

Survival in the presence of honey at $22{ }^{\circ} \mathrm{C}$ and $30{ }^{\circ} \mathrm{C}$ were assessed within one experiment, allowing direct comparison (Fig. 3). Longevity at $30{ }^{\circ} \mathrm{C}$ was significantly shorter for both taxa $\left(\chi_{2}^{2}=115.52\right.$, $\mathrm{P}<0.001)$. Although there was no significant interaction between taxa and temperature (taxa (as strata) $\times$ temperature: $\chi_{2}^{2}=1.504, \mathrm{P}=0.471$ ), Asaphes spp. females appeared to be affected more strongly than Dendrocerus spp. by a high temperature of $30{ }^{\circ} \mathrm{C}$ because at $22{ }^{\circ} \mathrm{C}$ they lived almost three times as long, and at $10{ }^{\circ} \mathrm{C}$ more than seven times as long.

\section{Cold tolerance}

Asaphes spp. females had a significantly lower mean chill temperature than Dendrocerus spp. (Wilcoxon rank test, $\mathrm{W}=15, \mathrm{P}<0.001)$. Asaphes spp. only stopped moving at a median temperature below freezing $\left(-0.17{ }^{\circ} \mathrm{C}\right)$, compared to $7.52{ }^{\circ} \mathrm{C}$ for Dendrocerus spp. (supplementary material Fig. S6). When raising the temperature, Asaphes spp. also resumed moving at a lower temperature (median $5.97{ }^{\circ} \mathrm{C}$ ) than Dendrocerus spp. (median $9.53{ }^{\circ} \mathrm{C} ; \quad \mathrm{W}=52$, $\mathrm{P}<0.001)$. $\left(\chi_{2}^{2}=115.52, \mathrm{P}<0.001\right)$, while there was no significant interaction between taxa and temperature $\left(\chi_{2}^{2}=1.504\right.$, $\mathrm{P}=0.471)$. For an explanation of boxplots, see Fig. 1

\section{Discussion}

Dendrocerus and Asaphes species coexist in (sweet pepper) greenhouses as hyperparasitoids of aphid mummies (Acheampong et al. 2012; Bloemhard et al. 2014; Jacobson 2011; Nagasaka et al. 2010). Here, we studied effects of temperature and food source on reproduction and longevity of these hyperparasitoids in an attempt to explain their coexistence and seasonal patterns in occurrence.

Asaphes spp. and Dendrocerus spp. females rejected parasitized aphids as hosts as expected because they are known as hyperparasitoids of aphid mummies (Sullivan and Völkl 1999). There was little effect of mummy age on reproductive success of Asaphes spp. and Dendrocerus spp., except for the oldest mummies (just prior to emergence of $A$. colemani) that were not suitable for development of either taxa. Dendrocerus spp. but not Asaphes spp. were able to reproduce in early mummies, when the mummy skin was still soft. These findings corroborate previous research on various species of Dendrocerus. In D. laticeps, mummy age did not affect parasitism success, developmental time, or sex ratio (Mitsunaga et al. 2014). Dendrocerus carpenteri can use mummies from right after mummification until just before the adult parasitoid emerges, although emergence of 
offspring seemed less successful in the youngest and oldest mummies (Walker and Cameron 1981). Old hosts may also negatively affect developmental time and size of D. carpenteri (Otto and Mackauer 1998), parameters that we did not measure here. Correspondingly, D. carpenteri preferred mummies of intermediate ages in choice tests (Chow and Mackauer 1999).

The low reproductive success of Asaphes spp. in the mummy age experiment may be explained from its lifetime reproduction pattern because we used females that had not been exposed to hosts before. Indeed, while Dendrocerus spp. starts reproduction immediately upon emergence, most Asaphes spp. females produce their first offspring after a few days (Table 1) (Buitenhuis et al. 2017). This difference may be associated with different patterns of egg maturation in these hyperparasitoid taxa. While D. aphidum Rondani emerges with approximately 15 mature eggs (Araj et al. 2008), our own observations suggest that Asaphes spp. females emerge with only a few. Host feeding in Asaphes may contribute to egg maturation and high fecundity over its lifetime (Buitenhuis et al. 2017), although the effect on egg load has not yet been studied. In other parasitoid species, host feeding can indeed influence longevity and/or reproductive success substantially (Burger et al. 2005; Heimpel and Collier 1996; Jervis and Kidd 1986).

Realised fecundity of Asaphes spp. and Dendrocerus spp. was in the range recorded in previous studies, confirming that Asaphes generally produces more offspring over its lifetime than Dendrocerus. Fecundity appears to vary considerably in these hyperparasitoid taxa, both between and within studies. For example, D. carpenteri produced 154 offspring at $20{ }^{\circ} \mathrm{C}$ on potato aphids parasitized by A. nigripes Ashmead (Buitenhuis et al. 2017), but just half as many at $19{ }^{\circ} \mathrm{C}$ on pea aphids parasitized by A. smithi Sharma \& Subba Rao (Walker and Cameron 1981). When D. laticeps was kept on honeydew of parasitized aphids, their lifetime fecundity on peach aphids parasitized by $A$. colemani was $<50$ at $25^{\circ} \mathrm{C}$ (Mitsunaga et al. 2014). Asaphes' fecundity appears to be even more variable, ranging from 50 (Mackauer and Volkl 1993) to over 800 for A. suspensus (Buitenhuis et al. 2017), and over 1000 for $A$. vulgaris Walker (Brodeur and McNeil 1994). Between studies, variation in fecundity may be due to the exact combination of aphid, primary parasitoid and hyperparasitoid species. Additionally, the food source offered to hyperparasitoid females likely has a strong impact on their longevity, and may have consequences for reproduction (Jervis et al. 2008), particularly in Asaphes because fecundity and longevity are positively correlated. Alternatively, higher temperatures may be less suitable for Dendrocerus and result in lower numbers of offspring (Buitenhuis et al. 2017; Mitsunaga et al. 2014). In this study, we therefore evaluated the effects of both factors-food source and temperature-on longevity.

Hyperparasitoid longevity was strongly influenced by food source, with the presence of sugar (in honeydew, nectar or honey) significantly enhancing longevity compared to food sources without sugar (water or mummies). Dendrocerus spp. females survived the longest on aphid honeydew, and this was the only food source on which they lived longer than Asaphes spp. Interestingly, a recent study showed that $D$. aphidum lives longer on several typical honeydew sugars, than on melibiose, a sugar that only occurs in floral nectar (Goelen et al. 2018). Moreover, D. aphidum consumed the highest amounts of melezitose, a sugar that is primarily found in aphid honeydew and rarely in flowers. The congeneric $D$. carpenteri responds behaviourally to aphid honeydew, which served as an arrestant cue (Buitenhuis et al. 2004). Combined, these findings suggest that Dendrocerus species are well adapted to honeydew. This adaptation may contribute to their success early in the growing season in greenhouses when sweet pepper plants do not flower yet and honeydew may be the only food source available.

Longevity of Asaphes spp., on the other hand, was highest on a combination of mummies, sweet pepper flowers and aphid honeydew, i.e. the 'complete' suite of food sources available in a greenhouse environment. In contrast to Dendrocerus, Asaphes can feed on aphid mummies, thereby gaining proteins or free amino acids from host haemolymph (Jervis and Kidd 1986). These nutritional elements are required for egg maturation in synovigenic parasitoids (Le Ralec 1995), and may also enhance life expectancy (Heimpel and Collier 1996). Apparently, a combination of host food and sugars derived from non-host food sources increases life expectancy of Asaphes spp. most, a phenomenon that has been described in detail for the parasitoid Aphytis melinus DeBach (Collier 1995).

Our experiments demonstrate that Asaphes spp. and Dendrocerus spp. do well at low temperatures. 
Females of both taxa oviposited at $5{ }^{\circ} \mathrm{C}$, although only a few females successfully produced offspring. Oviposition success increased rapidly with temperature for Dendrocerus spp. Survival at $10{ }^{\circ} \mathrm{C}$ in the absence of honey was only approximately one week for both taxa, but humidity was not controlled in our climate chamber and adding water twice per week possibly led to sub-optimal humidity. With honey, longevity of hyperparasitoid females was much higher at $10{ }^{\circ} \mathrm{C}$ compared to $22{ }^{\circ} \mathrm{C}$. Asaphes spp. in particular lived extremely long at this low temperature, with a third of the females living for more than six months. Coma chill experiments showed that Asaphes spp. females stopped moving at just below $0{ }^{\circ} \mathrm{C}$ and Asaphes spp. was thus more cold tolerant than Dendrocerus spp. that stopped moving between 7 and $8{ }^{\circ} \mathrm{C}$. Together, these findings suggest that hyperparasitoids of both taxa are able to survive the period between the final harvest, generally in November in Dutch sweet pepper greenhouses, and planting the new crop, between mid-December and early January. During this time, the greenhouses are not heated and temperatures may drop to $5{ }^{\circ} \mathrm{C}$, close to the ambient temperature in the Netherlands in December. If it can be demonstrated that hyperparasitoids indeed overwinter in empty greenhouses, this could explain the early presence in the year noted by Bloemhard et al. (2014), where D. aphidum was already observed in February and A. suspensus in March. However, our results do not support the hypothesis that Dendrocerus spp. are less affected by low temperature and therefore appears earlier in the season. Alternatively, Asaphes spp. may become more dominant later in the season because it copes better with high temperature. Again, our findings do not support this hypothesis. Lifespan of both hyperparasitoid taxa was much reduced at $30{ }^{\circ} \mathrm{C}$ compared to $22{ }^{\circ} \mathrm{C}$, and this reduction seemed stronger in Asaphes spp. than in Dendrocerus spp. Nevertheless, it remains to be studied how these hyperparasitoids respond to more realistic summer greenhouse temperature regimes that are variable and include extremes above $30{ }^{\circ} \mathrm{C}$.

In summary, experiments with two laboratory colonies of Dendrocerus and Asaphes species show that these hyperparasitoids are long-lived and thrive on food sources that are naturally available in commercial greenhouses. This could contribute to the persistence of hyperparasitoid problems in protected cultivation, where they may indeed affect the efficiency of biological control (Acheampong et al. 2012; Bloemhard et al. 2014; Gomez-Marco et al. 2015; Schooler et al. 2011). The success of Dendrocerus early in the season may partially be explained by its good performance on honeydew that is likely the only food source during this period. Additionally, compared to other abundant hyperparasitoid taxa, Dendrocerus may be more efficient at finding its host (Buitenhuis et al. 2005), and is known to forage even at night (Völkl and Kranz 1995). We also observed that Dendrocerus spp. females are immediately active in host searching once they emerge as adults-which is not the case for Asaphes spp.- and we are further investigating their host searching behaviour. Differential effects of decreased or increased temperature do not appear to explain seasonal patterns of Asaphes and Dendrocerus presence in greenhouses. Instead, Asaphes may do better later in the season due to its long lifespan and long reproductive period. Once it has settled in a greenhouse, Asaphes can remain present for a long time and can easily overcome periods of low host availability when sugar sources are available. Understanding the dynamics of hyperparasitoid populations in greenhouses is necessary to develop solutions to hyperparasitoid problems in this environment. This requires monitoring studies with good resolution in time and space to validate suggested trends in greenhouses.

Acknowledgements We appreciate the assistance of Frank van Neerbos, Jasper Schinkel, Rik Waenink, Vincent Wilk, Niki Brans, and Marcha Vlasveld with experimental work, and Olga Kostenko with statistical analyses. We acknowledge Vitalis Biologische Zaden B.V. (Voorst, The Netherlands) for providing us with sweet pepper seeds and Koppert Biological Systems (Berkel en Rodenrijs, The Netherlands) for providing Aphidius colemani parasitoids. Marjolein Kruidhof and Gerben Messelink of Greenhouse Horticulture \& Flower Bulbs (Wageningen University and Research, Bleiswijk, The Netherlands) are thanked for their help in chill coma experiments. This work is part of the research programme Scents of Success (project number 13848 granted to L.E.M. Vet), which is financed by the Netherlands Organisation for Scientific Research (NWO), domain TTW.

\section{Compliance with ethical standard}

Conflict of interest The authors declare that they have no conflict of interest.

Open Access This article is distributed under the terms of the Creative Commons Attribution 4.0 International License (http:// creativecommons.org/licenses/by/4.0/), which permits 
unrestricted use, distribution, and reproduction in any medium, provided you give appropriate credit to the original author(s) and the source, provide a link to the Creative Commons license, and indicate if changes were made.

\section{References}

Acheampong S, Gillespie DR, Quiring DJM (2012) Survey of parasitoids and hyperparasitoids (Hymenoptera) of the green peach aphid, Myzus persicae and the foxglove aphid, Aulacorthum solani (Hemiptera: Aphididae) in British Columbia. J Entomol Soc B C 109:12-22

Araj SE, Wratten S, Lister A, Buckley H (2008) Floral diversity, parasitoids and hyperparasitoids - a laboratory approach. Basic Appl Ecol 9:588-597

Benjamini Y, Hochberg Y (1995) Controlling the false discovery rate: a practical and powerful approach to multiple testing. J R Stat Soc Ser B 57:289-300

Bloemhard CMJ, van der Wielen M, Messelink GJ (2014) Seasonal abundance of aphid hyperparasitoids in organic greenhouse crops in The Netherlands. IOBC/WPRS Bull 102:15-19

Brodeur J, McNeil JN (1994) Life history of the aphid hyperparasitoid Asaphes vulgaris Walker (Pteromalidae)-possible consequences on the efficacy of the primary parasitoid Aphidius nigripes Ashmead (Aphidiidae). Can Entomol 126:1493-1497

Buitenhuis R, McNeil JN, Boivin G, Brodeur J (2004) The role of honeydew in host searching of aphid hyperparasitoids. J Chem Ecol 30:273-285

Buitenhuis R, Vet LEM, Boivin G, Brodeur J (2005) Foraging behaviour at the fourth trophic level: a comparative study of host location in aphid hyperparasitoids. Entomol Exp Appl 114:107-117

Buitenhuis R, Harvey JA, Vet LEM, Boivin G, Brodeur J (2017) Comparing and contrasting life history variation in four aphid hyperparasitoids. Ecol Entomol 42:325-335

Burger JMS, Kormany A, van Lenteren JC, Vet LEM (2005) Importance of host feeding for parasitoids that attack honeydew-producing hosts. Entomol Exp Appl 117:147-154

Chow A, Mackauer M (1999) Host handling and specificity of the hyperparasitoid wasp, Dendrocerus carpenteri (Curtis) (Hym., Megaspilidae): importance of host age and species. J Appl Entomol 123:83-91

Collier TR (1995) Host feeding, egg maturation, resorption and longevity in the parasitoid Aphytis melinus (Hymenoptera, Aphelinidae). Ann Entomol Soc Am 88:206-214

Fergusson NDM (1980) A revision of the British species of Dendrocerus Ratzeburg (Hymenoptera: Ceraphronoidae) with a review of their biology of aphid hyperparasites. Bull Br Mus (Nat Hist) 41:255-314

Goelen T, Baets D, Kos M, Paulussen C, Lenaerts M, Rediers H, Wackers F, Jacquemyn H, Lievens B (2018) Gustatory response and longevity in Aphidius parasitoids and their hyperparasitoid Dendrocerus aphidum. J Pest Sci 91:351-360
Gomez-Marco F, Urbaneja A, Jaques JA, Rugman-Jones PF, Stouthamer R, Tena A (2015) Untangling the aphid-parasitoid food web in citrus: can hyperparasitoids disrupt biological control? Biol Control 81:111-121

Graham MWRdV (1969) The Pteromalidae of North-Western Europe (Hymenoptera, Chalcidoidea). Bull Br Mus (Nat Hist) $16: 77-83$

Harvey JA (2008) Comparing and contrasting development and reproductive strategies in the pupal hyperparasitoids Lysibia nana and Gelis agilis (Hymenoptera: Ichneumonidae). Evol Ecol 22:153-166

Harvey JA, Cloutier J, Visser B, Ellers J, Wackers FL, Gols R (2012) The effect of different dietary sugars and honey on longevity and fecundity in two hyperparasitoid wasps. J Insect Physiol 58:816-823

Hazell SP, Pedersen BP, Worland MR, Blackburn TM, Bale JS (2008) A method for the rapid measurement of thermal tolerance traits in studies of small insects. Physiol Entomol 33:389-394

Heimpel GE, Collier TR (1996) The evolution of host-feeding behaviour in insect parasitoids. Biol Rev Camb Philos Soc 71:373-400

Hothorn T, Hornik K, van de Wiel MA, Zeileis A (2006) A Lego system for conditional inference. Am Stat 60:257-263

Jacobson R (2011) Sweet pepper: further development of IPM solutions for aphid infestations. Report PC295b. Agriculture and Horticulture Development Board, Kenilworth

Jervis MA, Kidd NAC (1986) Host-feeding strategies in hymenopteran parasitoids. Biol Rev Camb Philos Soc 61:395-434

Jervis MA, Ellers J, Harvey JA (2008) Resource acquisition, allocation, and utilization in parasitoid reproductive strategies. Annu Rev Entomol 53:361-385

Kassambara A, Kosinski M (2018) survminer: drawing survival curves using 'ggplot2'. R package version 0.4.2

Keller LJ, Sullivan DJ (1976) Oviposition behavior and host feeding of Asaphes lucens an aphid hyperparasitoid. J N Y Entomol Soc 84:206-211

Le Ralec A (1995) Egg contents in relation to host-feeding in some parasitic Hymenoptera. Entomophaga 40:87-93

Mackauer M, Volkl W (1993) Regulation of aphid populations by aphidiid wasps: does parasitoid foraging behavior or hyperparasitism limit impact. Oecologia 94:339-350

Mangiafico S (2018) rcompanion: Functions to support extension education program evaluation. $\mathrm{R}$ package version 1.13 .2

Mitsunaga T, Nagasaka K, Moriya S (2014) Development and parasitization of an aphid's secondary parasitoid, Dendrocerus laticeps (Hymenoptera: Megaspilidae), on Aphidius colemani (Hymenoptera: Braconidae). Appl Entomol Zool 49:511-518

Nagasaka K, Takahasi N, Okabayashi T (2010) Impact of secondary parasitism on Aphidius colemani in the banker plant system on aphid control in commercial greenhouses in Kochi, Japan. Appl Entomol Zool 45:541-550

Otto M, Mackauer M (1998) The developmental strategy of an idiobiont ectoparasitoid, Dendrocerus carpenteri: influence of variations in host quality on offspring growth and fitness. Oecologia 117:353-364 
Prado SG, Jandricic SE, Frank SD (2015) Ecological interactions affecting the efficacy of Aphidius colemani in greenhouse crops. Insects 6:538-575

R Core Team (2018) R: A language and environment for statistical computing. R Foundation for Statistical Computing, Vienna, Austria. http://www.r-project.org

Schooler SS, De Barro P, Ives AR (2011) The potential for hyperparasitism to compromise biological control: why don't hyperparasitoids drive their primary parasitoid hosts extinct? Biol Control 58:167-173

Sullivan DJ, Völkl W (1999) Hyperparasitism: multitrophic ecology and behavior. Annu Rev Entomol 44:291-315
Therneau T (2015) A package for survival analysis in S. version 2.38

Völkl W, Kranz P (1995) Nocturnal activity and resource utilization in the aphid hyperparasitoid, Dendrocerus carpenteri. Ecol Entomol 20:293-297

Walker GP, Cameron PJ (1981) The biology of Dendrocerus carpenteri (Hymenoptera, Ceraphronidae), a parasite of Aphidius species, and field observations of Dendrocerus species as hyper-parasites of Acyrthosiphon species. N Z J Zool 8:531-538 